\title{
Why Learners Choose Plagiarism: A Review of Literature
}

\author{
Deanna Klein \\ Minot State University, Minot, North Dakota, USA
}

deanna.klein@minotstateu.edu

\begin{abstract}
Through a review of literature, this paper presents a theoretical foundation for understanding why learners may choose to plagiarize both online and on ground. Ethical theories, social desirability, perceptions of plagiarism, and demographics and academic dishonesty in relation to the reasons learners choose to plagiarize are presented. Web sites that encourage plagiarism and online tools that are available to detect plagiarism are discussed.
\end{abstract}

Keywords: Plagiarism, ethical theory, social desirability, perceptions of plagiarism, demographics, academic dishonesty, online plagiarism detection

\section{Introduction}

Many actions performed by learners in higher education could be considered dishonest. Central Connecticut State University (2004) reports actions such as falsifying data, presenting another's words or ideas as one's own, or cheating on assigned work as being dishonest. Godfrey and Waugh (n.d.) describe dishonest practices as copying from previous assignments or from books, inappropriate student collaboration on assignments, inappropriate assistance from relatives, inappropriate reference to crib notes, cheating during exams, and lying to faculty when missing deadlines.

According to McCabe \& Trevino (1993, 1997, 2002), learner cheating is becoming a campus norm, institutions of higher education are lacking an honor code and adequate penalties, and there is little chance that a learner will get "caught" - due in part by lack of faculty support for academic integrity policies. McCabe supports these statements based on his involvement with many research studies on academic integrity. McCabe has studied learner self-reported academic dishonesty involving 2,100 learners surveyed in 1999, faculty self-reported academic dishonesty involving over 1,000 faculty members on 21 campuses in 1999, and the influence of honor codes on academic dishonesty in 1990, 1995, and 1999 involving over 12,000 learners and 48 campuses (Center for Academic Integrity, n.d.). As a result of these studies, McCabe reports one-third of the participating learners admitted to serious test cheating and half admitted to one or more in-

Material published as part of this publication, either on-line or in print, is copyrighted by the Informing Science Institute. Permission to make digital or paper copy of part or all of these works for personal or classroom use is granted without fee provided that the copies are not made or distributed for profit or commercial advantage AND that copies 1) bear this notice in full and 2) give the full citation on the first page. It is permissible to abstract these works so long as credit is given. To copy in all other cases or to republish or to post on a server or to redistribute to lists requires specific permission and payment of a fee. Contact Publisher@InformingScience.org to request redistribution permission. stances of serious cheating on written assignments. One-third of the faculty reported that they were aware of learner cheating in their course in the last two years, but did nothing to address it (Center for Academic Integrity, n.d.). In reference to reported faculty's cavalier attitude on cheating, McCabe finds, as suggested by learner reporting, that the engagement of cheating is higher in courses where learners know faculty members 
are likely to ignore cheating (Center for Academic Integrity, n.d.). McCabe \& Treveno (2002) argue that Academic honor codes effectively reduce cheating. Surveys administered by McCabe demonstrate a positive impact of honor codes and learner involvement on academic dishonesty. Serious test cheating on campuses with honor codes is typically $1 / 3$ to $1 / 2$ lower than the level on campuses that do not have honor codes. The level of serious cheating on written assignments is $1 / 4$ to $1 / 3$ lower (Center for Academic Integrity, n.d.).

Researchers believe that the act of plagiarism is growing in higher education (Anderson, 2001; Ashworth, Bannister, \& Thorne, 1997; Braumoeller, \& Gaines, 2001; Bushweller, 1999; Center for Academic Integrity, 2001; Fain \& Bates, 2002; Groark, Oblinger, \& Choa, 2001). The advent of the Internet has made a wealth of information available for learners to research for writing papers (Weinstein \& Dobkin, 2002). Some learners are using the availability of information via the Internet to improve the quality of their work; however, others are using it to simply "cut and paste" information into the paper. Because there is such a range of information that is relatively easy to access, learners can easily plagiarize the work of others. McKenzie (1999) reports on teachers complaining that new technology is making it easier for learners to plagiarize. Under the "new plagiarism," as McKenzie refers to plagiarism using technology, learners are now able to access and save numerous documents with little reading, effort, or originality as opposed to the huge amount of time it took for learners to move words from an encyclopedia to white paper and changing a few words in an effort to avoid plagiarism.

The purpose of this paper is to provide a theoretical foundation for understanding why learners may choose to plagiarize. This paper is organized as follows. The paper presents a review of literature that includes ethical theory, social desirability, perceptions of plagiarism, and demographics and academic dishonesty linking them to the reasons learners choose to plagiarize. The paper concludes with a discussion on Web sites that encourage plagiarism and online tools that are available to detect plagiarism.

\section{Ethical Theory}

\section{Morality and Ethics}

McShane and Von Glinow (2005) describe ethics as the study of moral values involving actions that may be right or wrong or result in good or bad outcomes. Sullivan and Pecorino (2002) further classify ethics by ethical theory and ethical principle. They suggest that ethical theory takes the most general point of view when interpreting ethical experience, obligations, or the role of reason. Ethical principles, on the other hand, are general rules of conduct that emerge or are derived from ethical theory. When discussing ethical principles, one should consider moral intensity and the ethical sensitivity as well (McShane \& Von Glinow, 2005). Moral intensity measures the degree to which the application of ethical principal is necessary. When the intensity of a moral issue increases, a higher degree of ethical consideration is necessary. Ethical sensitivity deals with a personal characteristic. The more ethically sensitive a person is, the better he/she is able to recognize the presence and importance of an ethical issue.

According to Lyons (2005), many Americans are finding the moral and ethical climate to be troubling. According to Gallup's annual Mood of the Nation poll, as taken in 2005, 59\% of Americans are somewhat or very dissatisfied with the ethical and moral climate of the country (Lyons, 2005). Only $7 \%$ of the remaining $40 \%$ are very satisfied with the ethical and moral climate of the country, and $33 \%$ are somewhat satisfied. Follow up interviews with some of the respondents resulted in diverse reasons for the responses. However, it should be noted that one of the concerns listed was plagiarism in the schools. The Gallup Poll also reports that the younger the respondent, those aged 18 to 29 , the more satisfied with the ethical and moral climate of the country. 
Sullivan and Pecorino (2002) consider morality to be a social phenomenon because moral behavior is based on situations in which humans are living with others. For example, inappropriate use of another's work is legally wrong in the United States and considered to be morally wrong by many people in the country. However, China doesn't have such a law, and plagiarism doesn't have the moral affect on Chinese learners studying in their country.

\section{Cultural Relativism}

Cultural values have an important influence on personal ethical behavior (McShane \& Von Glinow, 2005). For example, when referring to an institution of higher education, one would think the cultural environment is pretty stable and is usually understood by learners at some point. When the structure of the institution is further broken down, the culture within the major is even more obvious to the learner. However, Ashworth, Freewood, and Macdonald (2003) imply that this is a time of considerable change in higher education, and the changes effect the concern for increased plagiarism.

Changes in higher education include moving from the elite status to a mass-system. Changes in assessment are changing from formal proctored exams to a greater emphasis on coursework such as term papers and projects (Ashworth et al., 2003). The advances in technology have changed how learners work on assignments and papers (Scanlon \& Neumann, 2002). Scanlon and Neumann (2002) recommend research in the area of the new and next generation of learners that have been exposed to advanced technology from an early age to determine if the advances in technology have an influence on learners. Another change presented by Ashworth et al. (2003) is the increased focus on group-based learning. With the ambiguity on collective and individual ownership this method of learning may have an influence on the perception of academic honesty overall.

The culture of plagiarism itself may have been derived from such implementations as the copyright law, or the cultural history of the idea of individual originality, or contemporary cultural variations (Ashworth et al., 2003). Although the copyright law was originally intended to restrict competition among publishers, it has since evolved to protect the rights of authors. The idea of individual originality in regard to plagiarism is to explore creative and unique ideas as authors rather than repeatedly presenting materials from the existing literary world. The advances of technology have been a common consideration when studying plagiarism. Safo (1994) sees technology as a tool to use as an author, just as the chainsaw or laser printer or earlier technology, such as a carving device or pencil, are just tools. An example of contemporary cultural variations would be the perception Americans have of Chinese students being rote learners because the educational culture in China relies heavily on memorization (Pennycook, 1996). In America, this is considered plagiarism if the memorized work is used as the student's own work.

\section{Utilitarian Theories}

Utilitarianism is the idea of choosing the greatest good for the greatest number of people or to seek the highest degree of satisfaction to those affected by our decisions - all people are considered morally equal (McShane \& Von Glinow, 2005). The theory was developed by Benthem for English lawmakers in order to encourage decision making for the common good rather than their own social class (Sullivan \& Pecorino, 2002). The utilitarian theory is problematic because it focuses on the consequences and not the process for the accomplishment (McShane \& Von Glinow, 2005). If the focus is to achieve the greatest results, the ethical consideration in the process may be overlooked, such as in writing. If earning a grade or a degree is considered the greatest good to an individual or the family of the individual, perhaps choosing to plagiarize in order to achieve the grade or degree is the option a utilitarian learner will choose. 
Two types of utilitarian theory are act and rule (Sullivan \& Pecorino, 2002). The difference is that the act utilitarian only considers the single act or decision, and the rule utilitarian will look at the overall or long term consequences of the decision. An example would be a learner contemplating whether or not to plagiarize on a research paper. If the learner chooses to plagiarize, he or she will believe the best work was submitted and the consequences will be good. However, the rule utilitarian would consider that the paper will be turned in to the teacher and the plagiarism may be detected resulting in bad consequences.

Utilitarian was established as a dominant ethical theory by Jeremy Bentham and was further developed by John Stuart Mill in the mid and late $19^{\text {th }}$ century (Sullivan \& Pecorino, 2002). Although the two agree on most of the foundation behind the utilitarian theory, Mill considers moral implications along with the good consequences and the number of people it would be good for. Mill will make a decision that might not have the same good or pleasurable results as another, but understands it to be morally the better decision. A learner following Mill's theory would be less inclined to plagiarize than one following Bentham's theory.

\section{Kantian Theories}

Immanuel Kant is an influential philosopher from the 1700's whose philosophies have a profound effect on ethics. Unlike the utilitarian theory, Kant's theory on thinking and acting does place high value on ethics (McCormack, 2001). Kant does make the assumption that the consequences from some actions are just wrong even if they produce the most good for the most people. Furthermore, Kant considers the fact that not all people know what makes them happy and it is difficult to measure happiness.

Moral law is considered by Kant to be an instinctive sense, something that is part of our conscious or even deeper than our conscious (Sullivan \& Pecorino, 2002). Moral law is the source of human freedom and autonomy and is derived from human reason within oneself. Kant sees the basis for the theory of good as what lies in the intention or the will of a person. In this case, the decision or act is morally praiseworthy and done out of the sense of what is right rather than what the consequences are (Sullivan \& Pecorino, 2002).

Kant considers it a person's duty to apply human reason to determine the right or rational thing to do. Human reasoning is the search for universal laws that are central to human morality, the heart of the demand for impartiality and justice. A legal system, however, has been structured so that impartiality is avoided just as the universal law is created to remove impartial ideas and reasoning, rather than consider justice and morality.

\section{Social Desirability}

Bushweller (1999) reports that many educators consider the erosion of ethics in our self-centered society as the reason why learners are increasingly cheating. Other educators consider the rise in learner collaboration as a factor, while still others blame teachers for not caring or not bothering to deal with cheating. Finally, some blame the parents who don't hold their children accountable if they are caught cheating. In reality, there are a number of social factors that could influence learner cheating in higher education (Bushweller, 1999).

Several social theories may also influence why learners plagiarize. Cross and Brodt (2001) explain social projection theory as viewing people and places based on one's own beliefs, knowledge, or experience rather than on anything objective about the person or place. In this case, learners that plagiarize might anticipate that it occurs more often in higher education than it really does, but they want to believe plagiarism is rampant in order to excuse their own behavior. Social identity theory and self-categorization could also influence why learners plagiarize. The social identity theory assumes that people's perception of the world depends on the perception they have 
of themselves (Haslam, Eggins, \& Reynolds, 2003). People in this group will define themselves based on the group they belong to and feel an attached to. As an example, Young (2001) reports in the Chronicle of Higher Education that learners do not see the process of cut and paste without quoting or referencing as a problem. Today's learners are accustomed to downloading music, sharing files, and reading articles for free - making it seem acceptable to submit plagiarized work. Young (2001) quotes Donald L. McCabe, a professor at Rutgers University, as saying, "A typical attitude I hear from high school learners is 'if it's on the Internet, it's public knowledge, and I don't have to cite it"' (p.1).

If academic integrity is expected in higher education, faculty must play a vital role in socializing learners on an ethical culture (Lumpur, Jaya, Pinang, \& Miri, 1995). Lumpur et al. (1995) describe a learner's attitude about white collar crime. The learner's position is that if Donald Trump can get away with skipping out on billions in loan payments, then why can't other business people get away with white collar crime or petty theft? This student has based his perception of what is acceptable on the information he is getting in this world around him (McShane \& Von Glinow, 2005). Therefore, Lumpur et al.'s (1995) suggestion of socializing learners on an ethical culture is important and further suggests that prominent business leaders be included to send a clear message to the learners that unethical behavior is unacceptable, and, furthermore, ethical behavior will be rewarded, even in this competitive business climate. Including both the instructor and a business leader creates strong reinforcement on the importance of ethical behavior.

Peirce and Allshouse (1999) attribute cheating to peer pressure, insecurity, or striving for perfection. In a report by the Duke University Academic Integrity Assessment Committee (2001), a learner was quoted as saying "if you don't want cheating to go on here at Duke, you should work to have a more cooperative rather than competitive environment (p. 12)." This learner feels the competitive nature of the institution adds pressure to cheat in order to succeed. Some learners simply consider plagiarism as socially acceptable (Fain \& Bates, 2002). The belief that everyone or a large majority of peers frequently cheats or facilitates cheating makes the choice to cheat less difficult (Central Connecticut State University, 2004). However, a 1994 study at University of North Carolina-Chapel Hill (as cited by Peirce \& Allshouse, 1999) revealed that $89 \%$ of the freshmen surveyed indicated that they either disagreed or strongly disagreed with the statement, "Academic cheating in college courses is an acceptable behavior under certain circumstances." Even though these learners do not condone cheating, it still exists.

Bandura (1986, as cited by McCabe and Trevino, 1993) explains social learning theory as human behavior "learned through the influence of example" (p. 527). If learners are observing their peers cheating with nonexisting or minimal punishment, the learner is more apt to cheat as well. Under this theory, the burden to prove dishonesty rests on the professor, even though it is an unpleasant situation for everyone involved.

\section{Perceptions of Plagiarism}

For several reasons, learners have a different perception of what plagiarism is. In some cases, the learners have received ambiguous or conflicting education on plagiarism (Ashworth et al., 1997; Heron, 2001; Lathrop \& Foss, 2000; Peirce \& Allshouse, 1999; Weiss \& Bader, 2003). In other cases it is social identity where learners are comparing themselves to others (McShane \& Von Glinow, 2005). If learners perceive "everyone" to be a cheater or perceive faculty not to care about plagiarism, their perception on plagiarism may be skewed.

\section{Public Perception of Plagiarism}

Weiss and Bader (2003) report that the public perception of academic dishonesty in higher education is that it is a serious problem. Because public perception is so poor, they argue it will be dif- 
ficult to change the perception where mistrust and disinterest are prevalent. Peirce and Allshouse (1999) suggest that situations such as take-home tests, previous tests kept on file, and online services that practically beg learners to download ready-to-submit papers only exacerbate the public perceptions on cheating. Another finding by Heberling (2002) indicates the public perception on cheating is that it takes place online more than in the classroom on ground wherein the reality is that academic dishonesty takes place in both environments.

The results of a three study analysis by Education Testing Services (1999) indicates the general "public perception is that cheating is more prevalent and accepted today;" the respondents to the surveys see cheating "in many facets of life: politics, business, home, and school," and "collaborative environments like the Internet are making the definition of cheating even murkier" (p. 1). ETS also reports that " $56 \%$ of educators and $31 \%$ of the public (including parents, and learners) say that they hear about cheating incidents. However, only $35 \%$ of educators and $41 \%$ of the public (including learners and parents) agree that there is a problem with cheating on tests" (p. 2).

The fact that these respondents know plagiarism is taking place but don't consider it to be a problem makes addressing the problem from a preventative nature in higher education more important.

\section{Learner Perception of Plagiarism}

Many researchers argue that there is ambiguity on what is perceived as academic dishonesty among learners (Ashworth et al., 1997; Heron, 2001; Lathrop \& Foss, 2000; Peirce \& Allshouse, 1999; \& Weiss \& Bader, 2003). Learners have claimed that they don't know what instructors consider to be dishonest or cheating. An example of an area of ambiguity might include peer collaboration and knowing to what extent the collaboration is considered inappropriate (Weiss \& Bader, 2003). Lathrop and Foss (2000) agree that there is an inherent conflict between an instructor's desire to assign collaborative work to learners for preparation for future careers and the need to teach learners to do their own work. The point of crossing the line to cheating may differ by each instructor (Williams, 2001).

Even though there is ambiguity among learners on what constitutes academic dishonesty, there is also a cavalier attitude toward cheating by learners in higher education (ETS, 1999; McCabe, n.d.; McCabe \& Trevino, 1993, 1997). Research consistently reports that learners feel their cheating will not affect others (Weinstein \& Dobkin, 2002). Some researchers argue that students understand plagiarism to be a victimless crime; the only person that plagiarism is cheating is oneself. Studies on self-reported plagiarism indicate that plagiarism is accepted among their peers (Gillespie, 2003), the likelihood of getting caught is slim, and if the learner does get caught, the punishment will be minimal (Weinstein \& Dobkin, 2002). Gibbs (1975, as cited by McCabe and Trevino, 1993) suggests that learners will not be deterred from misconduct, in this case cheating, unless they perceive they will get caught and that the punishment is perceived to be severe. Learners will simply weigh the cost and benefits of plagiarizing based on their personal beliefs (Weinstein \& Dobkin, 2002). The potential cost is the probability of getting caught and the perceived punishment. The perceived benefit is based on learner perception of how much plagiarism will improve his or her grade. Under this theory, faculty must establish policy, inform learners of the policy, and enforce the policy with strict consequences in order to deter plagiarism in the course.

Learners accepting plagiarism as the "norm" are the people responsible for the future "civil society and the economy" (Gillespie, 2003, p. 30) and, unfortunately, this cavalier attitude of learners is not ending at graduation, but is continuing with resume fraud, crib notes for the CPR exam, and altering of other learner scores (ETS, 1999). In 1993, Sims published an article on the relationship between academic dishonesty and unethical business practices (as cited by Gillespie, 2003). Sixty people were surveyed and $91 \%$ of the respondents admitted they had been dishonest in college 
and $98 \%$ of the respondents admitted to dishonest work behaviors. The author of this study concludes that his data is consistent with the results of a 2001 study by Nonis and Swift (as cited by Gillespie, 2003) who found that many students accept academic dishonesty as acceptable behavior and that learners that are dishonest in college are more likely to carry the dishonesty into the work place.

For learners to have this cavalier attitude toward dishonesty is of concern because, in most cases, institutions of higher education have a learner conduct code and in many cases this code is published right on the course syllabus. What learners don't understand is the credibility of their alma mater and that their degree is at risk due to this behavior.

\section{Demographics and Academic Dishonesty}

Donald McCabe (as cited by ETS, 1999) reports overall personal indicators of learners who selfreport cheating in higher education to be business or engineering majors, more often men, who are preparing for business and learners with either a low or a high GPA. Cizek (1999) reviewed research on academic dishonesty and concludes that, although studies over time indicate males admit to academic dishonesty at a higher rate than women, the proportion of males and females reporting are about equal. Also, Cizek (1999) concludes that females have admitted to academic dishonesty as often as males under certain circumstances. In addition to gender, Cizek (1999) and McCabe and Trevino (1997) have reported data on the impact age may have on the engagement of academic dishonesty. In both cases, the researchers have found that the engagement of academic dishonesty decreases as age increases and nontraditional learners tend to cheat less than traditional aged learners.

The Center for Academic Integrity (CAI) summarized a review of literature from studies conducted in 1990, 1993, 1995, 1999, and 2001 (Center for Academic Integrity, 2001). The result of this review indicates a slow increase in academic dishonesty as learners' progress through the elementary and junior high grades. The peak age appears to be high school grades 11 and 12 with the trend slowly declining as the learner progresses through college (Center for Academic Integrity, 2001). Additionally, this review by CAI is consistent with the argument presented by McCabe and Trevino (1997) that engineering and business students report academic dishonesty at a higher rate than other disciplines. On the other hand, in a study by Nowell and Laufer (1997), computer science majors reported the highest level of academic dishonesty. CAI concurs with McCabe and Trevino (1997) in that males report academic dishonesty at a higher rate than females. McCabe and Trevino indicate that the higher incident of males reporting may have an effect on the engineering and business fields as they tend to be male dominated. Finally, studies show that as a GPA decreases, learners report a higher level of academic dishonesty (Center for Academic Integrity, 2001). Researchers suggest that perhaps learners feel they have less to lose if the cheat with a lower GPA than those with a higher GPA (Nowell \& Laufer, 1997).

\section{On Ground and Online Demographics}

Learners plagiarize for many reasons. In some cases learners are overwhelmed by assignments, procrastinate until they run out of time, or simply have too many responsibilities that contribute to each of the aforementioned reasons. It is important to understand the demographics of learners that report plagiarism in order to identify meaningful policies to encourage an environment of academic integrity.

Clayton (2001) provides demographic statistics on national enrollment in higher education from The Chronicle Almanac, 2001-2: The Nation. According to Clayton, "The Chronicle Almanac reports $62.7 \%$ of students enrolled in two and four year institutions in fall 2000 under the age of 25 and $37.3 \%$ over 25 . Analysis of the national full-time and part-time enrollment shows $72 \%$ of 
all students enrolled attend school full-time, while $28 \%$ attend part-time, and of the part-time students, $59.2 \%$ and $60.3 \%$ in two and four year institutions, respectively, are above the age of 25 " (2001, p. 3).

Halsne \& Gatta (2002) conducted a study to identify learning characteristics of learners taking online courses with learners taking the same course on ground. In their literature review, Halsne and Gatta (2002) identify learners who use technology for the delivery of courses in higher education as "more mature, more diverse, and display varying degree of readiness" (p. 1). Also, these learners have "various commitments and cannot relinquish their current jobs for the sake of education" (Halsne \& Gatta, 2002, p. 1). Other contributing variables include geographic restrictions or restrictions by their work schedules. The findings of Halsne and Gatta's own study show a higher number of women taking online classes than men. The women responded that they work outside of the house - primarily full-time. Heberling's (2002) research found that online learners are primarily married or divorced with children living at home. Online education provides working adults or adults with families with another delivery option that may be more conducive to their specific lifestyles.

Kramarae's study on women learning online (2001) also identifies an average online learner as a woman, 34 years old, employed part-time, and with previous college credit. Kramara reports that many of the women have children and work on their courses either late at night or early in the morning. The on ground learners were typically male, not married, under 25 years old, and had no dependent children living at home. The typical on ground learner was a full-time learner and is employed only part-time.

To evaluate The Chronicle Almanac's statistics, the data reported by Halsne and Gatta (2002), and the results from Kramarae's (2001) study, one would have to acknowledge that the general characteristics indicate a higher percent of learners take online courses for the flexibility the delivery offers for a slightly older learner with commitments beyond school. However, to complicate that theory, Hurst (2001) reports that at many campuses up to $75 \%$ of the learners enrolled in online courses are also resident learners taking classes on campus.

\section{Encouraging Plagiarism - Selling Papers Online}

The issue of plagiarism has been around for many years. According to Standler (2001), the commercial sale of term papers dates back to the late 1960s by people offering "academic research services." The added benefit of the Internet is that the text does not even need to be rekeyed; a simple copy/paste will suffice. Even though it is difficult to determine how common plagiarism is; one thing is certain - that there is an abundance of paper mill sites available for learner access.

One anonymous writer told his story about how he makes a living writing papers for students (Dante, 2010). In the past year, Dante (pseudonym) estimates he has written roughly 5000 pages of scholarly literature for subjects that vary widely and include subjects such as history, cinema, labor relations, and ethics. Dante has worked for an online company that generates tens of thousands of dollars a month by writing for cheating students. These students are willing to pay a handsome fee for a quick turn-around and for Dante to follow their specific instruction. With a custom paper, plagiarism is much more difficult to detect, and therefore, the student does not typically get caught.

Fain and Bates (2002) list many links to paper mill sites available for learner access. Some of these sites are free and some require a fee of different sorts. There are, however, no guarantees of quality or validity. Also, if a learner doesn't see a topic of choice, a paper can be custom written for an excessive fee. For example, Chris Pap's Essay Database (free), found at Chuckies College Resources http://www.chuckiii.com/, offers papers for a variety of prices depending on how fast the customer needs it. In one case, the prices range from $\$ 49.95$ per page for 8 to 23 hour re- 
sponse to $\$ 19.99$ per page for a seven day or longer turnaround time. It should be noted, however, that the Web site has the following quote posted at the bottom of the page, "Users of this website are hereby advised that Student Network Resources, Inc. is the parent company of various sites and also provides custom services for other websites. Any services provided by these websites are governed by the Terms and conditions section of this website. Users are further advised that Student Network Resources strictly prohibits the copying, reproduction, or plagiarism of any materials purchased from any of its websites. Violators may face civil and/or criminal penalties. The copying or reproduction of this website without expressed written consent of Student Network Resources is strictly prohibited." Even though Chuckies College Resources publishes this statement, it is difficult to determine what the consequences would be and the likelihood of getting caught.

Coshe's Reports found at http://www.cyberessays.com offers a variety of essays grouped in topics such as Art, Politics, English, or History. Prewritten example papers are available or custom written papers can be purchased. Coshe's report listed The Doctor found at http://www.fas.harvard.edu/-dberger/papers/; however, the site is no longer available. A widely know site called SchoolSucks found at http://www.schoolsucks.com/ promotes itself as the most popular term paper and free home work site. SchoolSucks has over 60,000 papers available for $\$ 9.95$ a page.

While Fain and Bates (2002) have primarily listed Internet paper mill sites, Weisbard (2004) has included a list of sites from university course web pages and department sites that are accessible via the WWW. Weisbard's sites include Social Science Paper Publisher found at http://www.sspp.net/. Weisbard reports that this site offers papers by undergraduates, graduate learners, and faculty. The site was public until July 2003 when restricted access was noted, and in November 2003 the site was no longer in operation. However, current access to http://www.sspp.net is available under the name Study Services Provider Portal. The content of this page is a listing of many online and distance education opportunities such as Phoenix Online and Devry University are listed. Access to Social Science Paper Publisher was not located.

Other sites listed by Weisbard (2004) are made available by the National Undergraduate Research Clearinghouse sponsored by the National Science foundation and Missouri Western State College, Barbie: the Image of Us All offered by University of Virginia, Classics: Women in Antiquity offered by Tufts University, and Peace Feminism in International Relation offered by the University of Denver. Ethics and Law on the Electronic Frontier offered by MIT is said to be "an archive of exemplary papers written by learners over several years" (Weisbard, 2004, p. 2).

Even though there are numerous opportunities for learners to purchase a research paper, several states have enacted laws to make it unlawful to sell term papers, essays, reports, and so on (Standler, 2000). For this reason, most Web sites will post a statement that inappropriate intent for cheating or plagiarism is not permissible. In the case of a state without a specific law regarding the unlawful sale of research papers, misuse can still result in legal action; the argument of "aiding and abetting fraud in obtaining a college degree" (Standler, 2000; p. 6) has been used. The 1972 State v. Saksnitt case (as cited by Standler, 2000) prosecuted in New York is an example of legal action for charging $\$ 1.90$ per page for a term paper in the company's stock and $\$ 3.85$ per page for a custom written paper. The argument for legal action is on the basis that Saksnitt is aiding and abetting learners in fraudulent behavior in attempt to earn a diploma or degree.

\section{Electronic Detection Tools}

Web sites are available for accessing electronic plagiarism detection tools. Electronic detection can be used in a number of different ways (Weisbard, 2004). A good search engine such as google.com or altavista.com can be utilized by submitting a stream of text from the paper. Or a 
commercial plagiarism detection site may be utilized by submitting the entire document for plagiarism analysis.

The Center for Intellectual Property (2005) at University of Maryland University College has listed several detection services Web sites. One example is Copycatch at http://www.copycatch.freserve.co.uk/. However, access to this site was not available. Essay Verification Engine at http://www.canexus.com/eve/index.shtml offers a plagiarism detection service for $\$ 19.99$ with unlimited submissions. The submitted papers are checked against EVE's database, which includes only Internet sources. Glatt Plagiarism Services at http://www.plagiarism.com/ offers a computer program that requires the learner to cut and paste into the program their written assignment. The software will remove every fifth word and the learner is to replace the word. The theory behind this method is that each individual has his/her own writing style and therefore, should be able to supply the missing word. Learners suspected of plagiarizing would need to prove the appropriate word in order to demonstrate authenticity of the submitted work. MyDropBox.com at http://www.mydropbox.com uses the Internet and institutional databases to detect plagiarism in a learner's submitted paper. MyDropbox.com promotes itself as the most comprehensive search of sources available.

TurnItIn.com will be the plagiarism detection Web site used for this study. Like MyDropbox.com, Turnitin.com claims to have the most comprehensive database of sources available for plagiarism detection (Turnitin.com, n.d.). Groark, Oblinger, and Choa (2001) describe turnitin.com as a portal for users registered with the company. Users may be either faculty using the site to detect plagiarism or learners who want verify that they have properly used references and properly cited the references. In either case, the paper will be checked against the turnitin.com database of electronic documents. The database "contains learner papers, papers posted online, material from academic Web sites, and documents indexed by major search engines" (p. 3). The Web site for turnitin.com also includes journals and books in its list of available sources (Turnitin.com, n.d.). Additionally, the papers submitted to turnitin.com will remain in the database further building the archive and will continue to detect existing learner papers; in turn, this should prevent the recirculation of papers on campus (Groark et al., 2001; Turnitin.com, n.d.).

Turnitin.com has tried to keep the process of submitting a paper simple. The instructor or learner submits the paper using a "proprietary search engine" (Groark et al., 2001). Turnitin.com responds using an "originality report." This report indicates the probability of plagiarism in terms of percentages. In addition to the percentage plagiarized, the source is given for the recipient to verify the detected plagiarism. This process can be completed in 24 hours, depending on the length of text and the level of demand (Groark et al., 2001; Turnitit.com, n.d.).

A technical review of plagiarism detection software was performed for the Joint Information Systems Committee at University of Bedfordshire located in Luton (Bull, Collins, Coughlin, and Sharp, 2001). Bull et al. (2001) use a five star rating scale (excellent, good, acceptable, poor, and unsatisfactory) to rate a variety of electronic detection sites. Turnitin.com is reportedly good in developer's stability, good in speed of response, excellent in clarity of reports, good in accuracy of reports, and poor in reliability of software/service.

The Center for Intellectual Property (2002) at University of Maryland University College also developed a Faculty and Administrators Guide to Detection Tools and Methods. Several detection sites, including turnitin.com were profiled. Some limitations of using plagiarism Web site detection have been identified. For example, only electronic format is searched; books and other learner works may not be included in an electronic format. In addition, subscription literature databases are almost never accessible for electronic plagiarism detection. Detected words can be identified as plagiarism, but thoughts and ideas cannot be; in some cases, and for various reasons, 
works marked as "plagiarized" may in fact not be plagiarized (Virtual Academic Integrity Laboratory, 2002, pg. 3).

While there are some limitations with plagiarism detection Web sites, Braumoeller and Gaines (2001) found plagiarism software to be successful and merits use in a wide variety of classroom situations. Braumoeller and Gaines published a study using learners in a university setting as their population. The learners submitted an approximately five page paper. The learners in one section received a written warning regarding plagiarism, and the instructor also gave an oral warning against plagiarism. The other group of learners was not warned. These authors then submitted the papers to a program called Essay Verification Engine, or EVE, version 2.1.

After the learners in the study by Braumoeller and Gaines (2001) submitted their papers, but before they were informed the papers would be submitted for plagiarism detection, they were asked to complete a survey. The focus of this survey was to determine if the written and oral warning deterred learners from plagiarizing. This may be the reason the authors did not disclose specifics on the survey, but used the information to compare learner's estimates of plagiarism rates with the percentage of plagiarism detected by the detection site. Across both sections - plagiarism detection and survey results $-40 \%$ plagiarism was detected and reported at the blatant level, and the maximum estimate of causal plagiarism was $80 \%$. Across both sections, the means values for plagiarism were $60 \%$ original, $32 \%$ causal, and $8 \%$ blatant. This study by Braumoeller and Gaines was conducted in 2001; it is important to mention that detection sites available today have increased in sophistication in both technology and access to resources for the database.

\section{Conclusion}

Whether learners lack proper education on what accounts for plagiarism, have misperceptions of what plagiarism is, or perceive a lack of consequences for their actions, learner plagiarism exists, both online and on ground, and some fear it is becoming an academic norm. There are several theories on why learners choose plagiarism over academic honesty. If the mood of the nation is shifting to dissatisfaction with our society's ethical and moral climate as literature indicates, the question becomes what moral and ethical behaviors are shaping learner behavior in our country. To further compound the issue, some argue the culture of higher education is shifting from an elite status to a mass system and assessment in higher education is changing to more group based learning or research paper requirements rather than the traditional proctored tests more directly measuring individual comprehension, which moves away from individual learner accountability.

In addition to overcoming the perception of people in our society compromising their ethical and moral beliefs, there is now an abundance of electronic paper mill sites available for learners to access existing research. While these sites print a disclosure indicating copying or reproduction from their website is strictly prohibited, there is temptation for those who are overwhelmed by assignments, procrastinate until they run of time, or have too many responsibilities. However, there are also electronic detection tools to be utilized by both learners and faculty to help instill awareness about plagiarism and to provide a tool for faculty and learners to understand how plagiarism is detected and what constitutes plagiarism or academic dishonesty. Ultimately, it is im-

portant to educate students about what constitutes plagiarism, the repercussions of plagiarism, and what tools are available to enhance research as opposed to perpetuating plagiarism.

\section{References}

Anderson, C. (2001). Online cheating: A new twist to an old problem. Student Affairs E-Journal, 2. Retrieved September 14, 2004 from http://www.studentaffairs.com/ejournal/Winter_2001/plagiarism.htm 
Ashworth, P., Bannister, P., \& Thorne, P. (1997). Guilty in whose eyes? University students' perceptions of cheating and plagiarism in academic work and assessment. Studies in Higher Education, 03075079, 22 (2).

Ashworth, P., Freewood, M. \& Macdonald, R. (2003). The student life world and the meanings of plagiarism. Journal of Phenomenological Psychology, 34(2).

Braumoeller, B. \& Gaines, B. (2001). Actions do speak louder than words: Deterring plagiarism with the use of plagiarism-detection software. The American Political Science Association Online. Retrieved September 14, 2004 from http://www.apsanet.org/PS/dec01/braumoeller.cfm

Bull, J., Collins, C., Coughlin, E., \& Sharp, D. (2001). Technical review of plagiarism detection software report: Prepared for the Joint Information Systems Committee, University of Luton. Retrieved February 4, 2005 from http://online.northumbria.ac.uk/faculties/art/information_studies/Imri/Jiscpas/docs/jisc/luton.pdf

Bushweller, K. (1999). Generation of cheaters. The American School Board Journal. Retrieved February 4 , 2005 from http://www.asbj.com/199904/0499coverstory.html

Center for Academic Integrity. (n.d.). Center for Academic Integrity - Research. Retrieved April 9, 2005 from http://www.academicintegrity.org/cai_research.asp

Center for Academic Integrity. (2001). Academic integrity: A research update. Retrieved April 9, 2005 from http://www.academicintegrity.org/mem cai_pub.asp

Center for Intellectual Property. (2005). Current issues and resources - Plagiarism. University of Maryland University College. Retrieved January 10, 2005 from http://www.umuc.edu/distance/odell/cip/links_plagiarism.htm.

Central Connecticut State University. (2004). Academic integrity - Faculty and student surveys. Retrieved December 22, 2004 from http://www.ccsu.edu/AcademicIntegrity/FacultyandStudentSurveys.htm

Cizek, G. (1999). Cheating on tests: How to do it, detect it, and prevent it. Mahwah, New Jersey: Lawrence Erlbaum.

Clayton, M. (2001). Who's online? A look at demographics of online student populations. V Congress of the Americas: Pueblo, Mexico

Cross, R., \& Brodt, S. (2001). How assumptions of consensus undermine decision making. MIT Sloan Management Review: Massachusetts Institute of Technology.

Dante, E. (2010). The shadow scholar. The Chronicle of Higher Education: The Chronicle Review. Retrieved December 01, 2010 from http://chronicle.com/article/article-content/125329/11

Duke University Academic Integrity Assessment Committee. (2001). Renewing our shared responsibility: Promoting academic integrity at Duke University.

Educational Testing Services. (1999). The educational testing service/add council campaign to discourage academic cheating. Retrieved December 22, 2004 from http://www.glass-castle.com/clients/wwwnocheating-org/adcouncil/research/

Fain, M. \& Bates, P. (2002). Cheating 101: Paper mills and you. Retrieved March 4, 2005 from http://www2.sjsu.edu/ugs/curriculum/cheating.htm

Gillespie, K. (2003). The frequency and perceptions of academic dishonesty among graduate students: a literature review and critical analysis. University of Wisconsin - Stout.

Godfrey, J. \& Waugh, R. (n.d.) Student's perceptions of cheating in Australian independent schools. Retrieved December 22, 2004 from http://edoz.com.au/educatoinaustralia/archive/features/cheat.html

Groark, M., Oblinger, D., \& Choa, M. (2001). Term paper mills, anti-plagiarism tools, and academic integrity. EDUCAUSE Center for Applied Research (ECAR). 
Halsne, A. \& Gatta, L. (2002). Online versus traditionally-delivered instruction: A descriptive study of learner characteristics in a community college setting. Retrieved November 28, 2004 from http://www.westga.edu/ distance/ojdla/spring51/halsne51.html

Haslam, S., Eggins, R., \& Reynolds, K. (2003). The ASPIRe model: Actualizing social and personal identity resources to enhance organizational outcomes. Journal of Occupational and Organizational Psychology, 76(1).

Heberling, M. (2002). Maintaining academic integrity in online education. Online Journal of Distance Learning Administration, V(1). Retrieved September 14, 2004 from http://www.westga.edu/ distance/ojdla/spring51/heberling51.html

Heron, J. L. (2001). Plagiarism, learning dishonesty or just plain cheating: The context and countermeasures in information systems teaching. Australian Journal of Education Technology, 17(3). Retrieved December 22, 2004 from http://www.ascilite.org.au/ajet/ajet18/leheron.html

Hurst, F. (2001). The death of distance learning. EDUCAUSE Quarterly, 24(3).

Kramarae, C. (2001). The third shift women learning online. Washington, DC: American Association of University Women Educational Foundation. Retrieved April 2, 2005 from http://www.aauw.org/research/3rdshift.cfm

Lathrop, A., \& Foss, K. (2000). Student cheating and plagiarism in the Internet era: A wakeup call. Libraries Unlimited Inc., Englewood, CO.

Lumpur, K., Jaya, P., Pinang, P., \& Bahru, J. (1995). Cheating among business students: A challenge for business leaders and educators. Journal of Management Education, 19(2). Retrieved September 14, 2004 from http://mgv.mim.edu.my/Articles/00417/960218.Htm

Lyons, L. (2005). Morality meter: Americans dissatisfied with ethical climate. Gallup Poll Organization. Retrieved April 29, 2005 from http://www.gallup.com/poll/content/print.aspx?ci=15154

McCabe, D. (n.d.). Center for Academic Integrity: Research. Retrieved December 2, 2004 from http://www.academicintegrity.org/cai_research.asp

McCabe, D., \& Trevino, L. (1993). Academic dishonesty: Honor codes and other contextual influences. The Journal of Higher Education, 64(5). Retrieved December 22, 2004 from http://www.jstor.org/

McCabe, D., \& Trevino, L. (1997). Individual and contextual influences on academic dishonesty: A multicampus investigation. Research in Higher Education, 38.

McCabe, D., \& Trevino, L. (2002). Honesty and honor codes. Academe. Retrieved April 5, 2005 from http://www.aaup.org/publications/Academe/2002/02JF/02jfmcc.htm

McKenzie, J. (1999). The new plagiarism: Seven antidotes to prevent highway robbery in an electronic age. From Now On: The Educational Journal, 7(8). Retrieved April 7, 2005 from http://www.fno.org/may98/cov98may.html

McCormack, M. (2001). Immanuel Kant (1724 - 1804) Metaphysics. The Internet Encyclopedia of Philosophy. Retrieved April 28, 2005 from http://www.utm.edu/research/iep/k/kantmeta.htm

McShane, S. \& Von Glinow, M. (2005). Organizational behavior: Emerging realities for the workplace revolution. New York: McGraw Hill.

MyDropbox.com (n.d.). Retrieved April 22, 2005 from http://www.mydropbox.com/technology.html

Nowell, C., \& Laufer, D. (1997). Undergraduate student cheating in the fields of business and economics. The Journal of Economic Education, 28(1).

Peirce, A., \& Allshouse, B. (1999). The influence of peer pressure on the reporting of academic dishonesty in a survey. Academic dishonesty at University of North Carolina: A collaborative study. Retrieved on December 22, 2004 from http://www.unc.edu/ bmize/teaching/english_12/academic_dishonesty/peirce\&allshouse.html 
Pennycook, A. (1996). Borrowing others' words: Text, ownership, memory, and plagiarism. TESOL Quarterly, 30 .

Safo, P. (1994). The place of originality in the information age. Journal of Graphic Design, 12(1).

Scanlon, P. \& Neumann, D. (2002). Internet plagiarism among college students. Retrieved from http://www.rit.edu/ pmsgsl/Ethics\%20in\%20TechComm/Internet\%20Plagiarism\%20among\%20Colle ge $\% 20$ Students.htm

Standler, R. (2000). Plagiarism in colleges in USA. Retrieved February 4, 2005 from http://www.rbs2.com/plag.htm

Sullivan, S., \& Pecorino, P. (2002). Ethics. Retrieved April 28, 2005 from http://www2.sunysuffolk.edu/pecorip/SCCCWEB/ETEXTS/ETHICS/CONTENTS.htm

Turnitin.com (n.d.). Retrieved January 4, 2005 from www.turnitin.com

Virtual Academic Integrity Laboratory. (2002). Faculty detection tools and methods - Choosing a detection tool. Retrieved February 4, 2005 from http://www.umuc.edu/distance/odell/cip/vail/faculty/detection tools/choosing.html

Weinstein, J. \& Dobkin, C. (2002). Plagiarism in U.S. higher education: Estimating Internet plagiarism rates and testing a means of deterrence. University of California, Berkeley.

Weisbard, P. (2004). Cheating, plagiarism (and other questionable practices), the Internet, and other electronic resources. Retrieved September 14, 2004 from http://www.library.wisc.edu/libraries/WomensStudies/plag.htm

Weiss, D. H., \& Bader, J. B. (2003) Undergraduate ethics at Homewood. Joint Curriculum Committee: Krieger School of Arts and Sciences and Whiting School of Engineering.

Williams, J. (2001). Flexible assessment for flexible delivery: Online examinations that beat the cheats. UniServe Science News, 18. Retrieved September 14, 2004 from http://science.uniserve.edu.au/newsletter/vol18/williams.html

Young, J. (2001). The cat-and-mouse game of plagiarism detection. The Chronicle of Higher Education Information Technology. Retrieved September 14, 2004 from http:/chronicle.com/prm/weekly/v47/i43/43a02601.htm

\section{Biography}

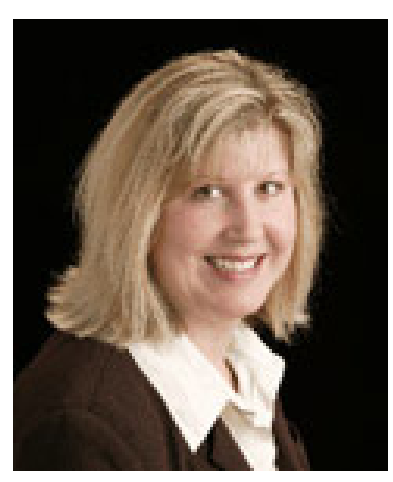

Dr. Deanna Klein is an associate professor in the College of Business, Department of Business Information Technology. In addition to teaching in the classroom, Dr. Klein teaches online classes and instructs continuing Education workshops. She is a professional member of the National Business Education Association (NBEA), International Association for Computer Information Systems (IACIS), Delta Kappa Gamma Chapter and a member and past President of the Minot High Marketing Advisory Board. Dr. Klein's current research interest is in the areas of distance learning and Management Information Systems. 